\title{
Comunicação e representações sociais nas relações de trabalho do pólo de confecções de Santa Cruz do Capibaribe, Pernambuco, Brasil
}

\author{
Betania Maciel* \\ Nelson Varela do Nascimento Neto**
}

\section{Resumo}

A partir da coleta de informações, por meio de investigação direta e pesquisa bibliográfica, objetivamos analisar hipotéticas influências recíprocas entre as relações de trabalho vinculadas ao pólo de confecções de Santa Cruz do Capibaribe, no Agreste Setentrional do Estado de Pernambuco, e práticas socialmente construídas e compartilhadas a partir das identificações das pessoas com as implicações do ambiente e do nicho de trabalho em questão. Além da observação direta em campo e da pesquisa bibliográfica, também acrescentamos alguns depoimentos das pessoas. Entre os resultados, ficaram claras influências geracionais nos direcionamentos de mercado, algumas consequências da sintonia entre as diferentes faixas etárias, assim como mudanças no cotidiano demarcada pelo intercâmbio constante entre "o local" e "o global".

Palavras chave: Trabalho. Hibridização. Mediações Culturais. Representações Sociais.

\footnotetext{
* Professora do Programa de Mestrado em Extensão Rural e Desenvolvimento Local (POSMEX), Departamento de Educação, Universidade Federal Rural de Pernambuco(UFRPE), Recife-PE, Brasil. Doutora em Comunicação Social, Mestre em Comunicação Rural. Máster em Ciência, Tecnologia e Sociedade: Comunicação e Cultura pela Universidade de Salamanca, Espanha.

E-mail: betaniamaciel@gmail.com

** Monitor da Escola de Saúde Pública, Secretaria de Saúde, Prefeitura Municipal de Recife. Recife-PE, Brasil. Sociólogo. Mestre em Extensão Rural e Desenvolvimento Local pela Universidade Federal Rural de Pernambuco.

E-mail: nelsonvarelaneto@gmail.com
} 


\section{Communication and social representations in work relationships in the clothing production pole of Santa Cruz do Capibaribe, Pernambuco, Brasil}

\section{Abstract}

With collecting information, came since presential contacts of field direct observation and bibliographic research, aimed to analyze hypothetic mutual influences between the Santa Cruz do Capibaribe clothing business cluster work relationships, in Pernambuco, Brazil, and the world interpretations among its staff and entrepreneurs, analyzing group identities and cultural organizations. Then, we tried to unveil the profile of the workers inside this ambience and their several appropriation and identification ways above the "work field" meaning, investigating faced with socially built and shared practices the person's identifications with environment and work field. Among the results, staid clear the generation reality interpretation such as influence on markets' direction, the constant everyday life's transformation marked by exchange with global perspective and harmony between generations.

Keywords: Work. Hybridization. Cultural Mediations. Social Representations.

\section{Comunicación y representaciones sociales en las relaciones} laborales del polo de confecciones de Santa Cruz do Capibaribe, Pernambuco, Brasil

\section{Resumen}

A partir de la recopilación de información directa a través de la investigación y la búsqueda de bibliografía destinada a analizar hipotéticas influencias recíprocas entre las relaciones de empleo vinculado al centro de ropería de Santa Cruz do Capibaribe, Agreste Septentrional del Estado de Pernambuco, y de la interpretación de la cultura de la organización en el mundo de las personas. Investigamos las prácticas socialmente construidas y compartidas de las personas con las implicaciones del medio ambiente y el nicho de trabajo que, además de la observación directa en el campo de búsqueda y la literatura, también añade algunos testimonios de las personas. Entre los resultados, la influencia generacional quedó claro mercado al que se dirigen, algunas consecuencias de la armonía entre los diferentes grupos de edad, así como los cambios en el diario demarcada por el constante intercambio entre el "local" y "global".

Palabras clave: Trabajo. Pólo de Roperías. Hibridación. Mediaciones Culturales. Representaciones Sociales.

\section{Introdução}

om ênfase no fato de que as identidades coletivas e as ativi-
dades culturais de cunho tradicional das comunidades que
se encontram em áreas rurais em processos de mudança do 
papel social de seus respectivos espaços se moldam entre as gerações e que existem implicações desta lógica, de forma específica, elegemos Santa Cruz do Capibaribe, no Agreste Setentrional de Pernambuco, como espaço amostral por se tratar de uma área de relativamente recentes mudanças no perfil das atividades laborais de sua população. $\mathrm{O}$ objetivo desta pesquisa é compreender a mudança nas relações de trabalho de uma região que transita na mudança de uma sociedade de base agrária para uma de base industrial e sua interferência nas representações sociais. Com o chamado "neo-rural" despontando para uma concentração maior de seu contingente populacional em atividades desvinculadas do setor de produção primário, a identidade cultural com o tradicional meio rural encontra outros determinantes para subsistir que não são mais aqueles relacionados necessariamente à relação com a natureza ou de um quantitativo predominante de pessoas envolvidas diretamente com essas mesmas atividades econômicas do setor de produção primário.

Decidimos realizar a técnica de pesquisa de grupo focal. Elaborar uma avaliação qualitativa, não-diretiva, para a coleta de dados, por meio de interações grupais. A escolha dos entrevistados esteve vinculada à necessidade de compreender o referencial simbólico, os códigos e as práticas daquele universo cultural específico, que não apresenta contornos muito bem definidos. Por meio de entrevistas foram levantados dados sobre as principais práticas adotadas e assim identificar sentimentos, percepções, atitudes e ideias dos participantes a respeito de determinado assunto. A energia gerada pelo grupo criou uma maior diversidade e profundidade de respostas, ou seja, um esforço combinado de pessoas que produz mais informações do que simplesmente o somatório das respostas individuais.

E, atualmente, com o pensamento já bastante compartilhado de que o desenvolvimento local é de autoria e de responsabilidade conjunta e mútua, não se chega a eximir do estado das responsabilidades que lhes são historicamente imputadas. Porém, admite-se que cada cidadão, no exercício do papel de sujeito histórico, está atribuído de encargos referentes ao processo de construção da vida coletiva e, de acordo com Pires (2005), tal linha de pensamento carrega consigo determinados conceitos como democracia, au- 
tonomia, autogestão, participação. É importante ainda dizer que também está presente na perspectiva de "desenvolvimento local" a tendência à exortação de um patrimônio natural e históricocultural de um dado território apto para dar subsídio a uma pluralidade de atividades de cunho meramente econômico, uma vez que logre concatenar os atores locais.

Esse "novo meio rural" é composto basicamente pela tríade caracterizada pelos grandes grupos de atividades principais: primeiramente por uma agropecuária moderna, baseada em commodities e intimamente ligada às agroindústrias; depois, por um conjunto de atividades não-agrícolas, ligadas à moradia, ao lazer e a várias atividades industriais e de prestação de serviços; e por fim, um conjunto de novas atividades agropecuárias, localizadas em nichos especiais de mercado (CHIKI; SILVA; ORTEGA, 1998, p.75).

As formas de organização social estruturadas sob a égide do relacionamento de trabalho e a ele diretamente vinculadas - incluindo o conjunto de normas e valores que regem os padrões de conduta -, estariam mudando a partir da flexibilização dos papéis sociais desempenhados dentro do respectivo campo de significação, assim como fazendo emergir novos papéis sociais.

Por isso realizamos a pesquisa no campo da recepção, tendo como orientação teórica principal a Teoria das Mediações Culturais, de Martín-Barbero, entendendo mediações culturais como "los lugares de los que provienen las construcciones que delimitan y configuran la materialidad social y la expresividad cultural (...)” (MARTÍN-BARBERO,1987, p.233). Optamos por avaliar a recepção por meio do estudo das representações sociais de Jodelet, que considera como "uma forma de conhecimento, socialmente elaborada e partilhada, que tem um objetivo prático e concorre para a construção de uma realidade comum a um conjunto social" (JODELET, 1995. p.32) uma forma de se interpretar a realidade erigida por um grupo social com o intuito de se conseguir uma uniformidade nas práticas sociais desse mesmo grupo.

Pressupõe-se que a saturação do potencial de absorção de mão-de-obra, devido à incompatibilidade entre oferta e demanda desse mesmo elemento nas grandes metrópoles brasileiras faça com que haja decréscimo do êxodo rural na medida em que aflora em 
sentido transversal um incipiente êxodo urbano. Esse novo fluxo de capital financeiro e humano somado à inserção de novas atividades e à capitalização de atividades tradicionais, até então excluídas do sistema econômico, fazem com que inúmeros municípios no interior do país venham emergir como cenários potenciais para o novo curso do desenvolvimento.

Mediante tão incisivas mudanças torna-se inelutável o fato de que as identidades culturais das comunidades envolvidas passem por um forte processo de transformação. Destacamos que não nos restringimos apenas a uma atitude metodológica cuja aplicação nos viabiliza um melhor entendimento das interconexões as relações culturais. Buscamos uma abordagem da generalidade das propriedades resultantes do contato entre os referenciais culturais, que vão além da simples divergência simultânea. Intentamos orientar para táticas de constituição da ascendência e legitimação da ordem hegemônica.

Para pôr em prática essa conexão entre relações de trabalho e os determinantes culturais, nossa metodologia foi enquadrada na categoria de estudo de caso, dentro de procedimentos empíricos que se orientam não tão-somente a partir da perspectiva das representações sociais, mas também das mediações culturais. Em síntese, Martín-Barbero se fundamenta na ideia de que não existe uma conexão linear e direta entre emissor, meio, mensagem e receptor, pois toda essa relação seria mediatizada. Também pusemos em prática um roteiro baseado no Modelo de Multimediações Culturais, de Orozco.

Validamente, fomos norteados pela nossa hipótese geral no trabalho que se constitui na asserção de que: as representações sociais das relações de trabalho implícitas nas dinâmicas de sustentabilidade e desenvolvimento econômico existentes no pólo de confecções de Santa Cruz do Capibaribe são mediatizadas pelas identidades culturais coletivas das pessoas envolvidas, dentre as quais escolhemos as que nós consideramos precípuas para a compreensão do estudo de recepção: mediação de heterogeneidade de temporalidades, mediação situacional da "aproximação e comvivência”, mediação de expectativas de consumo das mensagens do mass media e as mediações referenciais de gênero e idade. 
Buscamos a confirmação ou negação de que as representações sociais e os padrões de condutas coletivas influenciam no desempenho do sistema econômico do conglomerado do setor de confecções no Agreste Setentrional tomando o circuito ligado ao município de Santa Cruz do Capibaribe como estudo de caso especificado. Como consequência, nós oscilamos entre o desenvolvimento e a descoberta de hipóteses secundárias que subsistem de forma inerente à questão mais genérica e aqui se expressam em incógnitas. São elas: as formas de interpretação da realidade apresentadas pelas novas gerações estariam interferindo na atualização das orientações de mercado no pólo de confecções? O cotidiano no momento atual ainda estaria sendo alterado de forma contundente como se pressupõe que tenha acontecido em meados da época da mudança de atividade laboral e, ainda, suscetível a outras transformações de efeitos incisivos?

Como contribuição social da pesquisa, ambicionamos fornecer subsídios para a elaboração de estratégias que visem aprimorar e otimizar as possíveis formas de intervenção social focadas direta e indiretamente em contextos sociais similares ao pólo de confecções de Santa Cruz do Capibaribe, para que os interventores em potencial, sejam da iniciativa privada ou pública, realizem releituras, na medida do possível, mais acuradas acerca de suas formas de atuação.

\section{Teoria das representações sociais}

O limiar da conceitualização de "representação social" aconteceu a partir do trabalho de Serge Moscovici intitulado La psychanalyse, son image et son public, publicado no ano de 1961, ocasião na qual o autor explana acerca da representação social da psicanálise da população parisiense no final do decênio de 1950, numa tentativa de resgatar o dimensionamento social da Psicologia Social. Integrando-se a uma orientação psicossociológica, de origem europeia, ele exprobrou a corrente psicologista de tradição estadunidense que predominava com os seus estudos direcionados quase que somente para os processos psicológicos individuais.

Tendo Alport como um dos seus grandes representantes, essa linha de pesquisa norte-americana reforça a tendência do autor 
em enfatizar os processos psicológicos individuais sobre o social. Moscovici(1961, p.245)., buscando alternativas para se enquadrar nos parâmetros dessa corrente, diz:

Por representações sociais, entendemos um conjunto de conceitos, proposições e explicações originado na vida cotidiana no curso de comunicações interpessoais. Eles são o equivalente, em nossa sociedade, dos mitos e sistemas de crenças das sociedades tradicionais: podem também ser vistas como a versão contemporânea do senso comum.

Sua definição do conceito de representações sociais deixa clara a questão da interpessoalidade na construção dos processos comunicativos que constituem as representações, externando a validade delas para esses mesmos processos. Desta forma, ele respalda o encabeçamento no social a partir do conceito de representações sociais, lançando argumentos em prol da contingência de distinção entre as representações dos demais esquemas de pensamento coletivo, estabelecendo o que pode ser denominado de psicossociologia do conhecimento. Por isso as representações sociais carregam o status de teorias do senso comum, por se tratarem de teorizações resultantes da percepção, interpretação e consolidação dos significantes sociais dentro do espaço amostral delimitado pelo cotidiano.

A chamada "Teoria das Representações Sociais" se apresenta como proposição de uma marcha epistemológica para a elucidação dos fatos comuns na rotina da vida moderna, sendo aplicada por muitos autores na atualidade devido à sua plasticidade, desde nomes que trabalham o estudo das representações sociais na identidade pessoal ou coletiva seja no cenário nacional ou internacional, por meio de utilizações em campos empíricos variados, como pesquisas vinculadas a áreas diametralmente opostas ou reciprocamente complementares como o desenvolvimento rural e o planejamento urbano.

Moscovici (1961, p.277), assim define representação social:

Um sistema de valores, noções e de práticas tendo uma dupla tendência: antes de tudo instaurar uma ordem que permite aos indivíduos a possibilidade de se orientar no meio ambiente social, material e de dominar. Em seguida, de assegurar a comunicação entre membros de uma comunidade propondo-lhes um código para nomear e classificar de maneira unívoca as partes do seu mundo, de sua história individual ou coletiva. 
Jodelet (1989) afirma que as representações sociais podem ser definidas como os princípios geradores das tomadas de posição ligadas às inserções específicas dentro de uma reunião de correlações sociais. Esses princípios organizariam os processos simbólicos intervindo nas tais referências sociais, então, as tomadas de posição se efetuariam dentro das referências de comunicação e concerniriam a todo objeto de conhecimento uma importância dentro dos referenciais que se relacionam aos agentes sociais.

Antes de se concretizar a estruturação do modelo das representações sociais, a forma de pensar das massas, frequentemente denominada de "senso comum", era tida como um corpus de conhecimento quase inextricável, em comparação ao conhecimento científico um verdadeiro paradoxo, desprovido de facúndia e carregado de inumeráveis desvirtudes. Isso levou Moscovici a alegar que suas amofinações científicas acerca de tal forma de conhecimento e da fenomenologia comunicativa que lhe dá respaldo se encontram, principalmente, na inquirição do lugar em que se fecundaram e desenvolveram, e não onde o conhecimento científico teria sido pervertido e distorcido.

\section{A Perspectiva das mediações culturais}

Jesús Martín-Barbero(1987, 1995) sugere uma quebra com o protótipo hegemônico dos estudos de recepção; ou melhor, a do estudo de efeitos, que tende a conjecturar, determinar ou avaliar os resultados sob o respaldo da concepção funcionalista na qual a ato comunicativo se caracteriza pelo "chegar" de uma informação com a semântica já preparada, pronta de pólo a pólo, no sentido, da atribuição absoluta ao emissor da capacidade de persuasão e produção dos efeitos anelados na perspectiva do receptor.

A perspectiva das mediações culturais traz uma nova visão para os estudos da recepção, que passa a entendê-la como um estágio, "como uma espécie de um outro lugar, o de rever e repensar o processo inteiro da comunicação" (MARTİN-BARBERO, 1995, p.40). Entende assim que o vínculo dos fatores da comunicação não se concretiza de forma linear, e sim, ligada a uma urdidura de relações mediacionais. 
Na sua obra intitulada De los Medios a las Mediaciones, publicado pela primeira vez em 1987 (p.203), Jesús Martín-Barbero tece um conceito de mediação cultural como “(...) los lugares de los que provienen las construcciones que delimitan y configuran la materialidad social y la expresividad cultural [...]". As mediações culturais remetem às influências que a trama cultural implica sobre as maneiras nas quais as relações sociais são enleadas ou, como postula Orozco, [...] "es el lugar desde donde se otorga el sentido al proceso de la comunicación” (MARTIN-BARBERO, 1987, p.114).

\section{Modelo das multimediações culturais}

Após a operacionalidade prática do conceito das mediações culturais vir a ser bastante debatida por diversos expoentes da comunidade científica, Guillermo Orozco, no intuito de obter mais instrumentalização a partir do arcabouço conceitual de Martín-Barbero, elabora o Modelo das Multimediações, na qual são levadas em consideração uma série de fontes de mediação que são relevantes para o entendimento da relação dos expectadores com os meios, para que assim, os elementos subentendidos nessa pluralidade de mediações assumam os papéis de determinantes de estruturação e estabilização.

Ele diz que as mediações referenciais abarcam toda a gama de características que territorializam em um contexto específico, seja a faixa etária, o gênero, a raça, a etnia ou a classe social (OROZCO GOMES, 1997, p.118). Tais características dão margem para a contextualização, por parte do pesquisador, das referências que remetem ao receptor em questão.

\section{Representações em perspectiva mediacional}

Evidenciemos que em meio às alternativas teórico-metodológicas apresentadas pela Teoria das Mediações Culturais dos estudos de recepção, procuramos interpretar a significação que os receptores elaboram a partir das diversas instâncias que integram o processo de comunicação, não relevando apenas um exclusivo campo de emissão unilateral de mensagens sujeitas às interferên- 
cias das diversas mediações, mas sim um processo multilateral e também mediatizado, o que pode ser entendido como uma tentativa de compreensão das influências das imagens simbólicas ou dos conceitos formados pelos indivíduos envolvidos nas práticas laborais do pólo de confecções de Santa Cruz do Capibaribe e suas consequências dentro desse campo do universo significativo.

Nesse sentido, nos baseamos em algumas das mais importantes na influência do processo comunicativo desenvolvido entre os trabalhadores vinculados ao pólo de confecções e as pressões externas, advindas das demandas de mercado e das mudanças da conduta coletiva, consequentes da inserção em um cenário social estabelecido sob a influência do mass media e da ideologia capitalista de acumulação de divisas. Chamamos atenção, no entanto, para a observação de Orozco, de que o Modelo das Multimediações não está acabado e, sim, em formação, sendo dever do investigador a busca pela perceptibilidade intelectual acurada, capaz de complementá-lo na medida em que for usado no empírico.

\section{As distintas gerações}

Na ligação com as instâncias das camadas hegemônicas, aqui simbolizadas pelas pressões mercadológicas do mass media que geram tendências que produzem demandas de produção e de vendas, os confeccionistas realizam a fruição, compreensão e conformação das mensagens dessas dentro das próprias circunstâncias particulares de seus trabalhos.

Uma vez na qual identificamos, no empírico traço de múltiplas realidades temporais, uma "mediação de heterogeneidade de temporalidades" insurge como mediação precípua para o estudo, pois é por meio do empirismo que se torna possível observar a corporificação das diversas mediações interventoras do respectivo estudo (MARTÍN-BARBERO, 1995, p.40). A heterogeneidade de temporalidades é aqui categorizada não como mera diferença de idades, mas sobretudo pelas diferentes temporalidades de vivências no campo de significação abordado.

Mas utilizando como forma de organização didática as diferenças de idade em si, ressaltemos que os confeccionistas jovens, 
compreendidos até meados do início da superação dos 30 anos, afirmaram gostar de quando a influência televisiva interferia no seu cotidiano de trabalho, aquecendo as vendas, deixa clara a interferência das mensagens mass midiáticas dentro do seu ambiente diário, a vida de negócios alheios ao que se passa no resto do mundo, fora dos limites do agreste setentrional pernambucano, cada vez mais, cai por água abaixo. A rigor, alguns dos mais velhos, entendidos como aqueles com mais de sessenta anos, pareciam ainda viver um interminável período de adaptação a uma condição de interpenetração com o mundo exterior que em comparação às suas vivências parecem ainda incipientes e gera sentimentos imprecisos quanto a essa experiência:

Muitas vezes a roupa que a atriz usa na novela dá moda e acaba gerando vendagem 'prum' tipo de peça específico fazendo com que se tenha que fabricar mais um ou outro artigo, geralmente uma moda assim melhora os lucros, eu gosto quando a televisão faz acontecer esse tipo de coisa (Depoente $\mathrm{n}^{\mathrm{o}}$ 01, 26 anos).

Os trabalhadores veteranos em questão são filhos e netos de antigos trabalhadores rurais, ou até chegaram a debutar na vida trabalhista também como um trabalhador rural, na época, em que plantar, em terras próprias ou que lhes eram reservadas por um grande fazendeiro era a melhor alternativa para as famílias. Porém, o que chama mais a atenção nesse tipo de posicionamento é a demonstração de superação de fases pelo conglomerado de confecções, da adaptação às condições contemporâneas de sobrevivência competitiva no mercado.

Mas também não se pode negar que muitas das representações refletem as vivências anteriores em subempregos como reflexo das formações residuais de um passado que está vivo, mas que não se celebra, tão somente configura a memória como grupo. As experiências precedentes ficam marcadas e servem como bases para conjeturas das construções do presente. Eles revelaram memórias amargas desse passado. $\mathrm{O}$ trabalho sazonal gerava insegurança e desagregação de suas famílias. Assim, suas expectativas procuram encontrar saídas para essas lembranças residuais. 
Desta forma, percebemos nitidamente que há incorporações de ideias de amor às atividades. Estas são próprias em suas representações e podem ainda ser resultado das influências da vivência com as gerações pregressas que resguardavam características atribuídas ao homem do campo de forma estereotipada e associadas ao idílico e o poético devido ao apego à terra e à natureza. Recordemos aqui que, muitas vezes, os discursos sobre vivências de organização e orientação de trabalhadores rurais abordam os temas terra e tranquilidade de forma que se interpenetram como símbolo que não se dissociam, materializando, assim, a comunicação ideológica.

Em contrapartida, os mais jovens já demonstram um posicionamento pré-disposto à aceitação das mudanças de status quo nas suas rotinas laborais em função de transformações no panorama econômico e social, uma prédisposição tão flagrante que chega a se confundir com uma expectativa na verdade.

No que tange ao grupo de pessoas jovens, é mais fácil o processo de fruição e representação das mensagens do que se configura dentro de uma realidade de maior incidência de desestabilidades, ou seja, mais próximas da intermitência das variantes, sem desconsiderar algumas previsibilidades, alcançadas por meio das facilitações adquiridas a partir do planejamento das estratégias de condução dos seus empreendimentos. Os mais novos já reagem ativamente e em perspectiva de participação conjunta e legitimação dos estímulos emanados pelos instrumentos de manipulação ideológica que reforçam as mensagens de apelos consumistas que atendem aos interesses dos grupos socioeconomicamente hegemônicos.

Além disso, podemos destacar a oportunidade do ingresso mais fácil do que em outras áreas dos jovens no empreendedorismo, identificando alguns fatores que dão margem para essa ocorrência, tais como: a capacidade de se iniciar com um pequeno capital, o baixo custo de renovação das mercadorias, a parcial ausência de taxação tributária, a escassa necessidade de renovação constante do maquinário e a igualdade de condições de acesso ao mercado em relação aos empreendedores antigos.

Com efeito, as representações sociais do grupo de trabalhadores jovens apesar de, por vezes, carregadas de uma dose maior de otimismo, demonstram uma alternativa pela racionalização 
por meio da adoção de princípios de articulação com finanças de proximidade e do acompanhamento personalizado e ágil das possibilidades que o mercado pode oferecer e das demandas da clientela em potencial, daí emergem relações de confiança e compromissos entre os outros que compõem a mesma categoria, as formas de organização financeira, na maioria das vezes informais, e todas as outras instâncias que operem baseadas em objetivos comuns, por mais curto ou mais longo prazo.

Aqui em Santa Cruz tem espaço pra todo mundo, tem trabalho pra todo mundo, o negócio é só a pessoa ser desenrolada que consegue clientela e vende 'as mercadoria' direitinho e tira lucro sem problema, uma mão lava a outra, se eu não tenho uma mercadoria que o vizinho tem eu repasso (Depoente $\mathrm{n}^{\mathrm{o}}$ 02, 30 anos).

"O agiota que passa aqui atualmente até que é mais paciente, mas o anterior era muito estressado, queria chegar com grosseria, então eu quitei com ele e não peguei mais dinheiro. $\mathrm{O}$ que 'tá ' agora já não explora tanto nos juros e nem pega no pé, dá pra levar” (Depoente no 03, 27 anos).

\section{Os mais jovens e o consumo de confecções}

A respeito do "consumo como cenário de objetivação dos desejos", asseveramos com Martín-Barbero (1995, p.62), "que há uma dimensão, todos sabemos, fundamental em nosso consumo, é uma dimensão libidinal, dimensão desejante, e por mais que o desejo atravesse nosso consumo, permanentemente, orienta-o [...]". Para Canclini $(1983,1989)$, mesmo com todos os percalços de se por em evidência para apreciação pontos complexos sob um ponto de vista sociológico tal esfera da ação ou efeito de consumir precisa ser relevada. $\mathrm{O}$ autor adverte, porém, que se prime em considerar os contextos macrossociais onde se encontram os atos de consumo.

No grupo de trabalhadores com idade compreendida até 24 anos se implicam algumas variações da forma de receber e representar o campo de significação do ambiente de trabalho e do mundo de uma forma geral, tendo por muitas vezes como escopo o nível de experiência de vida dos mais velhos. Mas, essa questão não é peremptória, pois em muitos casos os mais jovens demonstraram estar mais infor- 
mados do que os mais velhos, quer seja por que circulam mais, por que acessam mais a internet ou vêem mais TV e, consequentemente, suas expectativas de consumo refletem tendências de mercado e essas tendências posteriormente podem orientar direcionamentos acerca das mercadorias que devam ser ofertadas ao público.

Eles têm aspirações de consumo no setor de vestiário que não mais se diferenciam das aspirações de qualquer adolescente da região metropolitana. Os referenciais de consumo são os mesmos e por vezes chegam até com uma força bem mais devastadora, pois até a concretização do consumo simbólico se torna mais difícil, quando se está distante dos grandes centros de compra de produtos de primeira linha que podem oferecer derivados como adereços e acessórios licenciados por grandes marcas e ofertados por valores menos astronômicos. Poderíamos identificar nesse ponto uma das hipotéticas causas propugnadoras da motivação da prática da pirataria de marcas famosas além daquela meramente financeira. Vale ressaltar que a pirataria é uma ocorrência facilmente observável em Santa Cruz do Capibaribe, mas no decorrer da pesquisa não encontramos nenhum confeccionista que declarasse realizar tal atividade.

Quando lhes perguntado se alguma vez se inspiraram na indumentária country para compor os seus visuais eles responderam predominantemente que uma vez ou outra já tiveram vontade, mas, em outra depois comentaram sorrindo que não gostavam de caracterizações que fizessem menções ao campo.

Esse negócio de calçar bota e chapéu de vaqueiro pra ir a show de forró já não 'tá' mais com nada, nem cantor de forró usa mais esse tipo de 'ropa'. Agora... sempre aparece um ou outro que gosta de se vestir desse jeito, mas só faz diminuir (Depoente no 04).

Essas representações acabam por ser compartilhadas pelas outras faixas etárias, pois refletem também as circunstâncias das cotidianidades das vidas das pessoas de toda a família, bem diferente de quando seus avôs viviam no campo, agora a família é composta por empreendedores do ramo de confecções seja na etapa de fabricação ou comercialização e de trabalhadores assalariados, em moldes bem mais próximos aos das grandes cidades. Convém 
enfatizar, entretanto, que essa assimilação se dá, fundamentalmente, por que as representações têm caráter coletivo.

\section{gênero feminino}

No que diz respeito às mulheres, a ocupação de um posto de trabalho significa uma mudança que rompe com a estabilidade da vida que teriam como apenas donas de casa. Na verdade, atualmente, quase nenhuma delas experimentou a condição de serem meras expectadoras das rotinas laborais dos maridos e a tirocínio de uma esposa de trabalhador rural informal, com toda a carga de insegurança que essa situação repercute em suas famílias, quase nenhuma mais compartilha. Elas são hoje profissionais que trabalham com os seus maridos e compartilham os êxitos e dificuldades de um mesmo mercado de atuação.

A depoente no 05, de 58 anos, por exemplo, é vendedora de roupas. Seu pai, na maior parte da vida, foi agricultor. Ela recorda das agruras de viver sem saber se a família iria ter alimento suficiente para realizar todas as refeições até a colheita seguinte.

Eu via meu pai se acabando na roça, pra ganhar tão pouco, no final do mês as coisas 'era contadinha', tanto esforço, tanto sacrifício, pra uma coisa que no final 'das conta' só dependia mais da chuva, do sol... e depois ainda podia estragar se não vendesse logo! (Depoente $\mathrm{n}^{\mathrm{o}} \mathbf{0 5}$ ).

As representações das menos jovens em um percentual maior estão ancoradas em suas experiências antes e durante a vida de subsistência a partir de recursos financeiros provenientes da exploração do setor primário de produção. Quando elas se referem ao estilo de vida anterior, deixam refletir as implicações da rotina entre a cidade e o campo, quando suas mães ou elas mesmas trabalhavam nas terras da propriedade na qual se habitava, plantando em limitados pedaços de terra produtos que depois eram vendidos geralmente aos sábados na feira juntamente com produtos que eram feitos manualmente, como artigos culinários e artesanatos.

Merece destaque a categoria de mulheres que dispensam a presença masculina no gerenciamento de seus negócios e 
ganham um novo status, o de provedora, além daquele de matrona, sábia, e conselheira, gozando de um maior poder na rede de relações sociais na qual se insere, até mesmo sobre muitos homens que participam de seus convívios. (MIELE et al, 1998) Essa realidade é perceptível nessa mulher que é respeitada por todos os entes, o ato de ir à luta, substituindo o perfil patriarcal por uma orientação matriarcal não foi considerado transgressor, elas com suas rezas se tornaram grandes arrimos para as famílias, não deixando a luta.

Há fatos que poderiam ser levados em conta ao tentarmos atribuir valores a essas representações femininas. Ressaltemos que muitos traços de conduta tradicionalmente atribuídos à bagagem de peculiaridades do gênero masculino na respectiva região, tais como o machismo e a falta de tolerância às mudanças de certas condutas estariam favorecendo a perda de espaço dos homens em diversos segmentos da sociedade, segmentos tais que estariam progredindo mais rápido que suas maneiras de inteligir a realidade, deixando ao encargo das mulheres a renovação dos ares no respectivo setor. Haveria ainda uma tendência de se remunerar as mulheres com menores cifras, o que aumentaria o fluxo do ingresso feminino no ramo, proporcionando-as uma melhora no acervo de experiências que resultaria no acúmulo de subsídios para o enfrentamento dos percalços previstos para futura incursão pelas atividades empreendedoras.

No que tange aos discursos feministas em suas construções, nenhuma mulher interpelada se referiu sequer implicitamente a quaisquer referenciais de luta pelos direitos femininos.

\section{Considerações finais}

No decorrer deste trabalho, com base no arcabouço teórico dos estudos de recepção na perspectiva das mediações culturais, buscamos entender as relações entre as dinâmicas e relações de trabalho versus as diversas formas de disposição social e interpretação da realidade dentro da cultura organizacional para o desenvolvimento local no pólo de confecções de Santa Cruz do Capibaribe. Essas relações laborais foram mediatizadas pela cul- 
tura do Agreste Pernambucano e estão submetidas a mediações dessa cultura, dentre as quais escolhemos as que pareceram mais proeminentes para o entendimento do estudo em questão tais como as referentes aos processos de aproximação e convivência e as expectativas de consumo de acordo com as mediações de gênero ou idade.

Os mais jovens se destacam pela sensibilidade mediante o contato com as tendências de comportamento contemporâneas, como sensores das mudanças de humores nas novas condutas coletivas que se convertem também em direcionamentos de mercado. Por isso que a respeito da convergência das mediações do estudo como geradoras de semântica, poderemos afirmar que campos de significação como o pólo de confecções de Santa Cruz do Capibaribe permitem estudos de caso emblemáticos para a identificação da apropriação dos significantes das classes hegemônicas pelas classes subalternas e as formas de consumo simbólico, que entre os mais jovens fica bem mais realçado, uma vez na qual a demanda por ampliação do capitalismo não sustenta a variegação de padrões culturais, de objetos e hábitos de consumo. Por isso, é aceitável a afirmação de que as novas gerações estão contribuindo para a atualização das orientações de mercado no pólo de confecções.

Entendemos, por meio dessas constatações, que os sistemas econômicos e culturais seguem entrelaçados reciprocamente, compondo uma unidade inextricável e é considerado preferencial o estudo das estruturas dos fenômenos simbólicos que erguem as estruturas econômicas e suas reciprocidades. $\mathrm{O}$ binômio local versus global remete reciprocamente nesse estudo de caso à oposição e a complementaridade.

Os elementos subjetivos de composição do perfil coletivo sofreram influências dos padrões de conduta tradicionais perpetuados ao longo dos tempos. Por isso é indubitável que o cotidiano está alterado de forma contundente em relação à época pregressa na qual as atividades principais eram do setor agrícola, mas ainda é claro que esse processo de forte mudança ainda continua vivo, no entanto já não está atrelado diretamente à alteração do status-chave de direcionamento econômico do município, e sim, às consequências dessa alteração, que implica na conexão desse 
território com as instâncias mais globalizadas da tessitura social que exaltam os valores das classes hegemônicas da sociedade que se encastelam nas grandes metrópoles. Como "efeito colateral", as expectativas de consumo e a ansiedade por "inovações" reproduzem o ritmo demarcado pelas camadas hegemônicas.

No que diz respeito à possibilidade de conflito entre as gerações sobre o ponto de vista das orientações de rumo dadas aos negócios, não se constatou nenhum embate aparente, as diversas gerações parecem cativar uma relevante sinergia na condução das estratégias e tomadas de decisões voltadas para a otimização dos lucros, aumento das condições de combatividade no mercado e melhoria das relações de vivência que proporcionem o bem-estar da cultura organizacional.

Compreendemos que a atual pesquisa demonstrou que os sentidos lançados pelas mediações externam demandas sociais e culturais dos trabalhadores. No ponto de vista das mediações que trabalhamos, foi possível perceber não apenas os sentidos produzidos para constatarmos uma ciência ou desconhecimento do espaço amostral, mas também o que essa semântica demarca sobre as interações entre cultura popular, cultura hegemônica e as demandas da respectiva população.

Em tempos de grandes antíteses, a pesquisa não intenta pôr à baila ambiguidades, mas contribuir para o embasamento de novos pontos de vista para o estudo da Ciência da Comunicação. E, diante do divulgado, gostaríamos de desfechar propondo para aqueles que estudam essa área, a iniciativa de incursão em singularidades de novas localidades ou até outras particularidades dessa mesma aqui abordada, para repensar a atuação de políticas e estratégias de comunicação para a Extensão Rural e o Desenvolvimento Local.

\section{Referências}

DOISE, W. Atitudes et representations sociales. In: Jodelet. D. Les representation sociales. Paris: PUF. 1998.

GARCÍA CANCLINI, N. As culturas populares no capitalismo. São Paulo: Brasiliense, 1983.

, N. Cultura transnacional y culturas populares. Lima: IPAL. 1988. 
, N. Ni Folklorico ni Massivo: Que es lo Popular? Dia-Logos de la Comunicación. Lima: FELAFACS. 1988.

, N. Culturas híbridas: el espacio comunicacional como problema interdisciplinário. Telos, Madrid, № 19, set/nov. 1989.

, N. Culturas híbridas y estrategias comunicacionales. Seminario "Fronteras Culturales: identidad y comunicación en América Latina", 16-18 de outubro de 1996.

, N. Culturas híbridas: estratégias para entrar e sair da modernidade. São Paulo: Edusp, 2006.

HARVEY, D. Condição pós-moderna: uma pesquisa sobre as origens da mudança cultural. 6.ed. São Paulo: Loyola, 1989.

HELLER, A. O cotidiano e a história. Rio de Janeiro: Paz e Terra, 1972.

HEREDIA, B. M. A. de. A morada da vida: trabalho familiar de pequenos produtores do Nordeste do Brasil. Rio de Janeiro: Paz e terra, 1979.

JODELET, D. Les représentations sociales. Paris: PUF, 1989

MARTìN-BARBERO, J. América Latina e os anos recentes: o estudo da recepção em comunicação social. In: SOUZA, Mauro Wilton (Org.). Sujeito, o lado oculto do receptor. São Paulo: Brasiliense, 1995. p.39-68.

, J.; REY, G. De los medios a las mediaciones: comunicación, cultura y hegemonía. México: G. Gili, 1987.

MIELE, N. A. et al.. Dimensão do Gênero na Promoção da Agricultura Sustentável. In: ARMANI, Domingos ET AL (Org.). Agricultura e pobreza: construindo os elos da sustentabilidade no Nordeste do Brasil. Porto Alegre Tomo Editorial/ Holanda: ICCO, 1998.

MOSCOVICI. S. La psycanalyse, son image et son public. 2.ed. Paris: Presse Universitaire de France, 1961.

OROZCO GÓMEZ, G. La investigación en comunicación desde la perspectiva cualitativa. Guadalajara: Instituto Mexicano para el Desarrollo Comunitário, 1997.

REDFIELD, R. The folk society. American Journal of Sociology, v.. 52, n. 4, 1947.

Recebido: 31.05 .2010

Aceito: 22.02.2011 